\title{
Single transversus abdominis muscle flap: Another possibility for large congenital diaphragmatic hernia repair
}

\author{
Alexis P. Arnaud, MD, Amandine Martin, MD, Edouard Habonimana, MD, and \\ Benjamin Frémond, MD, PhD, Rennes, France
}

From the Pediatric Surgery Department, Hôpital sud, CHU Rennes, Rennes, France.

No funding was provided to perform this study.

Ethics committee registry number: 15.92 .

Disclosures: Authors have nothing to disclose with regard to commercial support.

Received for publication Dec 2, 2015; revisions received April 11, 2016; accepted for publication May 1, 2016; available ahead of print May 25, 2016.

Address for reprints: Alexis P. Arnaud, MD, Pediatric Surgery Department, Hôpital sud, CHU Rennes, 16 Blvd de

Bulgarie, 35000 Rennes, France (E-mail: alexis.arnaud@chu-rennes.fr).

J Thorac Cardiovasc Surg 2016;152:925-6

$0022-5223 / \$ 36.00$

Copyright (C) 2016 by The American Association for Thoracic Surgery

http://dx.doi.org/10.1016/j.jtcvs.2016.05.005

Large-defect congenital diaphragmatic hernias are too large to be closed primarily and are characterized by diaphragm agenesis. This condition remains a surgical and intensive care challenge. ${ }^{1}$ Many different approaches have been described. Prosthetic patches are often used, but they face the major issue of a high recurrence rate ranging from $27 \%$ to $50 \%$. $^{2}$ Some reports in the literature describe muscle flap repair and although they are scarce and concern small series, they indicate that muscle flaps recur only in $0 \%$ to $4.3 \%$. For the past 20 years, our routine clinical practice has been to avoid patches by using a muscle flap to repair the defects that are too large for primary closure. We therefore present a simple, novel technique using a single-layer muscle flap based on the transversus abdominis muscle.

\section{PATIENTS AND METHODS}

Between 1995 and 2015, all newborn infants presenting with a large congenital diaphragmatic defect (ie, a defect too big to be closed primarily and characterized by diaphragmatic agenesis) underwent single-layer transversus abdominis muscle flap repair. We reviewed the data from the medical files of these children. This study was approved by our institutional research ethics board. Data are given as median (range).

\section{Surgical Technique}

Under general anesthesia, a newborn infant is placed in the supine position, with a roll under the thoracolumbar junction.

The abdominal cavity is opened with a transversal incision $5 \mathrm{~mm}$ above the umbilicus, extended to the side of the hernia (Figure 1,A). All layers are cut by monopolar diathermy. After reduction of the herniated organs, the anterior and posterior aspects of the diaphragm remnants are dissected (Figure 1, $B)$. The flap is fashioned. Using the tip of dissecting scissors in the avascular plane, the transversus abdominis muscle is divided from the 2 other layers of the upper lateral quadrant of the abdominal wall, joining the lower edges of the ribs. Sagittal incision of the aponeurosis between the transversus abdominis muscle and the rectus muscle frees the median edge of the flap to rotate it backward around the costal edge axis (Figure 1,A). After dissecting the edges of the diaphragmatic remnant (if present) all around the defect, the flap is sutured either to the muscle rim or to the ribs' periosteum using nonabsorbable interrupted stitches (Figure 1, $C$ and $D$ ). The abdominal muscle wall is then closed in 2 layers; that is, the superior sheet of the external and internal

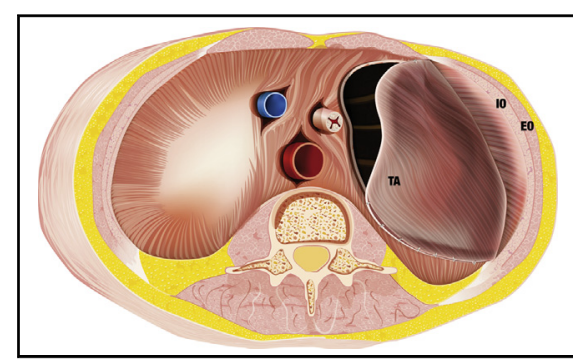

The transversus abdominis is dissected and stitched to the diaphragmatic remnant edges.

\section{Central Message}

We describe a new technique for muscle flap repair in patients with large congenital diaphragmatic hernia using only the transversus abdominis.

See Editorial Commentary page 927.

oblique muscles are sewn to an inferior sheet of the intact abdominal wall. In case of inadequate abdominal capacity, a staged closure of the abdominal wall is performed using a silo.

\section{RESULTS}

Sixteen newborn infants underwent the single muscle flap repair. All patients but 1 had a left hernia. Gestational age at birth was 37.6 weeks (range, 34-38.7 weeks) and birth weight was $2.875 \mathrm{~kg}$ (range, 1.78-3.2 kg). Surgery was performed at 29 hours of life (range, 4-96 hours) and all neonates were ventilated on high frequency oscillation. Procedure length was 2.5 hours (range, 1.5-3 hours). Surgery was performed in a neonatal intensive care unit or in an operating theatre in 14 and 2 cases, respectively. The abdominal wall was primarily closed in all but 2 patients who required a staged closure.

Twelve infants were discharged from the neonatal intensive care unit. Length of stay was 34 days (range, 20483 days) in the intensive care unit and 67 days (range, $32-483$ days) in the hospital. Four patients died in the neonatal intensive care unit: 3 due to refractory pulmonary hypertension ( 2 at day 1 and 1 at day 228) and 1 died as a result of Staphylococcus pneumonia at day 9.

\section{DISCUSSION}

Large congenital defect of the diaphragm that is not primarily closable remains a surgical challenge. Many 


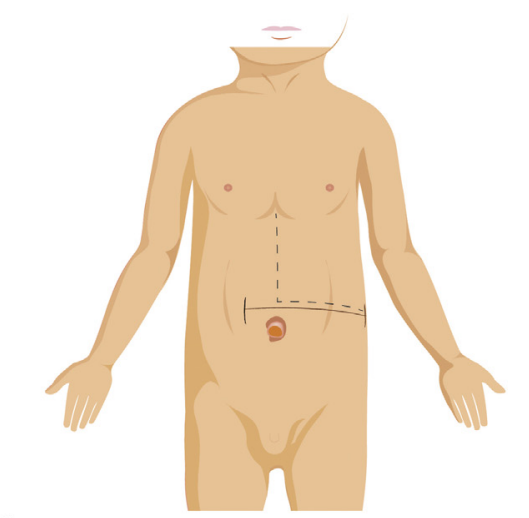

A

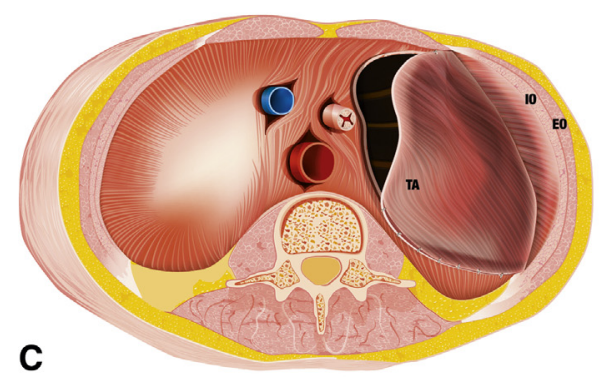

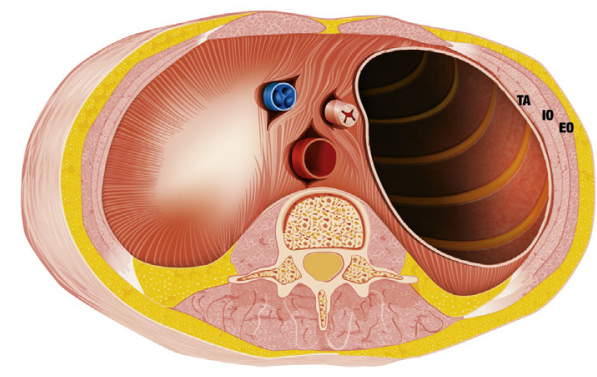

B

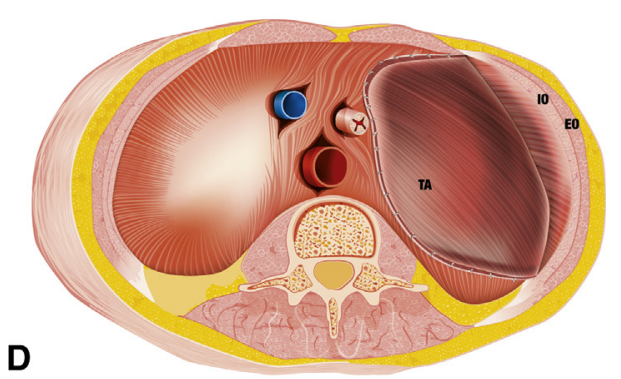

FIGURE 1. Surgical technique. A, Newborn infant is placed in the supine position. A transversal cutaneous incision is performed 5 mm above the umbilicus (continuous line). The muscle flap will be divided along the rectus abdominis (dotted line). B, View of a large congenital left diaphragmatic defect. Anterolateral abdominal wall consists of 3 muscle layers: transversus abdominis $(T A)$, internal oblique (IO), and external oblique (EO). C, After division of the avascular plan between the TA and the IO muscles, the flap is rotated backward and sutured to the diaphragmatic edges. D, Suture of the TA single muscle flap to the edges of the diaphragmatic remnant is completed. Two muscles, IO and EO, stay in place in the anterolateral abdominal wall.

techniques have been proposed. The abdominal muscle flap repair for diaphragmatic defect was first described in 1962, mobilizing the 3 layers of the abdominal wall, and was then modified by Simpson and Gossage in $1971 .^{5}$ They described a 2-muscle flap using the transversus abdominis and the internal oblique muscle swung posteriorly and stitched to the posterior muscle rim. In our technique, we also use an abdominal muscle flap, but we dissect only the transversus abdominis. The dissection plane allows for a high-quality, well-vascularized, and innervated flap. The transverse incision at the umbilicus level gives good exposure to the medial and posterolateral part of the defect compared with medial incision. This incision also facilitates the tailoring of a large muscle flap. Indeed, this technique has always produced a flap large enough to complete the defect closure without requiring prosthetic patch addition.

\section{CONCLUSIONS}

Considering the ease of the flap elevation and the large amount of well-vascularized tissue available, we believe that transversus abdominis muscle flap repair is a safe, simple, and suitable technique for repair of large, congenital diaphragmatic defect.

The authors thank Jean-Jacques Levrel (graphic studio, CHU Rennes) for designing the graphics and Luke Harper (Pediatric Surgery Department, CHU St Denis de La Reunion) for providing English revisions.

\section{References}

1. Lally KP, Lally PA, Lasky RE, Tibboel D, Jaksic T, Wilson JM, et al. Defect size determines survival in infants with congenital diaphragmatic hernia. Pediatrics. 2007; 120:e651-7.

2. Jancelewicz T, Chiang M, Oliveira C, Chiu PP. Late surgical outcomes among congenital diaphragmatic hernia $(\mathrm{CDH})$ patients: why long-term follow-up with surgeons is recommended. J Pediatr Surg. 2013;48:935-41.

3. Scaife ER, Johnson DG, Meyers RL, Johnson SM, Matlak ME. The split abdominal wall muscle flap — a simple, mesh-free approach to repair large diaphragmatic hernia. J Pediatr Surg. 2003;38:1748-51.

4. Barnhart DC, Jacques E, Scaife ER, Yoder BA, Meyers RL, Harman A, et al. Split abdominal wall muscle flap repair vs patch repair of large congenital diaphragmatic hernias. J Pediatr Surg. 2012;47:81-6.

5. Simpson JS, Gossage JD. Use of abdominal wall muscle flap in repair of large congenital diaphragmatic hernia. J Pediatr Surg. 1971;6:42-4. 